\title{
Cardiac magnetic resonance imaging of myocardial mass and fibrosis in primary aldosteronism
}

\author{
Marianne Aa Grytaas ${ }^{1,2}$, Kjersti Sellevåg ${ }^{3}$, Hrafnkell B Thordarson ${ }^{1,2}$, Eystein S Husebye ${ }^{1,2}$, \\ Kristian Løvås ${ }^{1,2}$, Terje H Larsen ${ }^{3,4}$ \\ ${ }^{1}$ Department of Clinical Science, University of Bergen, Bergen, Norway \\ ${ }^{2}$ Department of Medicine, Haukeland University Hospital, Bergen, Norway \\ ${ }^{3}$ Department of Heart Disease, Haukeland University Hospital, Bergen, Norway \\ ${ }^{4}$ Department of Biomedicine, University of Bergen, Bergen, Norway \\ Correspondence should be addressed to M A Grytaas: Marianne.grytaas@helse-bergen.no
}

\begin{abstract}
Background: Primary aldosteronism (PA) is associated with increased cardiovascular morbidity, presumably due to left ventricular (LV) hypertrophy and fibrosis. However, the degree of fibrosis has not been extensively studied. Cardiac magnetic resonance imaging (CMR) contrast enhancement and novel sensitive T1 mapping to estimate increased extracellular volume (ECV) are available to measure the extent of fibrosis.

Objectives: To assess LV mass and fibrosis before and after treatment of PA using CMR with contrast enhancement and T1 mapping.

Methods: Fifteen patients with newly diagnosed PA (PA1) and 24 age- and sex-matched healthy subjects (HS) were studied by CMR with contrast enhancement. Repeated imaging with a new scanner with T1 mapping was performed in 14 of the PA1 and 20 of the HS median 18 months after specific PA treatment and in additional 16 newly diagnosed PA patients (PA2).

Results: PA1 had higher baseline LV mass index than HS (69 (53-91) vs $51(40-72) \mathrm{g} / \mathrm{m}^{2}$; $P<0.001)$, which decreased significantly after treatment $\left(58(40-86) \mathrm{g} / \mathrm{m}^{2} ; P<0.001\right.$ vs baseline), more with adrenalectomy $\left(n=8 ;-9 \mathrm{~g} / \mathrm{m}^{2} ; P=0.003\right)$ than with medical treatment $\left(n=6 ;-5 \mathrm{~g} / \mathrm{m}^{2} ; P=0.075\right)$. No baseline difference was found in contrast enhancement between PA1 and HS. T1 mapping showed no increase in ECV as a myocardial fibrosis marker in PA. Moreover, ECV was lower in the untreated PA2 than HS 10 min post-contrast, and in both PA groups compared with HS 20 min post-contrast. Conclusion: Specific treatment rapidly reduced LV mass in PA. Increased myocardial fibrosis was not found and may not represent a common clinical problem.
\end{abstract}

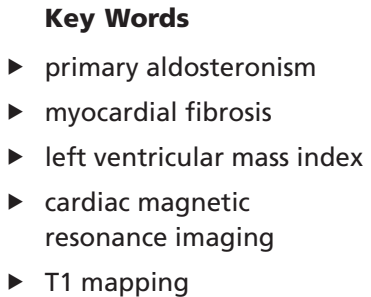

Endocrine Connections (2018) 7, 413-424

\section{Introduction}

Primary aldosteronism (PA) has been recognized as the most common cause of secondary hypertension (HT), with estimated prevalence of $5-12 \%$ of all hypertensive subjects $(1,2)$. In patients with refractory HT, PA may be present in up to $20 \%$ (3). Unilateral aldosterone-producing adenoma (APA) and bilateral idiopathic hyperplasia (IHA) are the main subtypes; unilateral hyperplasia, inherited

$$
\begin{array}{lr}
\text { http://www.endocrineconnections.org } & \text { ○ } 2018 \text { The authors } \\
\text { https://doi.org/10.1530/EC-18-0039 } & \text { Published by Bioscientifica Ltd }
\end{array}
$$

familial forms of PA and adrenal carcinoma are rare (4). Recommended treatment is adrenalectomy in unilateral PA and medical treatment with mineralocorticoid receptor antagonists in bilateral PA.

Several studies have demonstrated that PA patients have increased cardiovascular and renal morbidity compared with patients with essential $\operatorname{HT}(5,6,7,8)$.

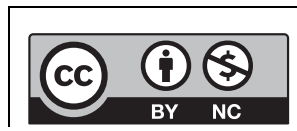

This work is licensed under a Creative Commons Attribution-NonCommercial 4.0 International License. 
Indeed, a recent study also demonstrated increased cardiovascular mortality (9). Increased prevalence of diabetes mellitus type 2 and the metabolic syndrome may also be present (10). Aldosterone, often associated with cortisol excess, causes deleterious effects on the cardiovascular system and increases metabolic risk, with end-organ damage that is at least partly independent of aldosterone effect on blood pressure (BP) (11). Experimental rat studies first demonstrated that chronic aldosterone infusion in the setting of high-salt intake induced oxidative stress and caused myocardial inflammation, accumulation of fibrillary collagen and subsequent interstitial fibrosis independent of the BP elevation $(12,13,14)$. The cardiac injury was reversed either with adrenalectomy or mineralocorticoid receptor antagonist treatment (15). Subsequent echocardiographic studies have demonstrated increased left ventricular (LV) mass in PA compared with essential HT with similar BP (16). Echocardiographic videodensitometric and ultrasonic backscatter signal analyses have shown alterations in myocardial texture in PA, suggestive of increased collagen deposition and fibrosis $(17,18,19)$. PA patients have more cardiac arrhythmias than in essential HT, presumably caused by cardiac fibrosis and/or LV hypertrophy $(5,20)$.

Specific PA treatment decreases LV mass both after adrenalectomy and after medical treatment with mineralocorticoid receptor antagonists in the long term, while echocardiographic studies with shorter follow-up time only showed significant reduction in LV mass after adrenalectomy $(21,22)$. In a recent meta-analysis, no difference in reduction of LV mass was found between adrenalectomy and mineralocorticoid receptor antagonist treatment after an average follow-up of four years, despite a larger reduction in BP after adrenalectomy (23).

Cardiac magnetic resonance imaging (CMR) offers a highly accurate, non-invasive, 3-dimensional assessment of cardiac structure, function and tissue characteristics. Contrast enhancement techniques including late gadolinium enhancement are accurate and reproducible in evaluating the presence of irreversible focal myocardial fibrosis/scars caused by myocardial infarction or hypertrophic cardiomyopathy $(24,25)$. Contrast enhancement is associated with adverse outcomes in several cardiac conditions $(26,27)$. However, the most commonly used contrast enhancement technique, late gadolinium enhancement, requires a comparison between affected and unaffected myocardium and may not be sensitive to early, potentially reversible diffuse myocardial fibrosis affecting the whole myocardium (28).

$$
\begin{aligned}
& \text { http://www.endocrineconnections.org } \\
& \text { https://doi.org/10.1530/EC-18-0039 }
\end{aligned}
$$

Recently, T1 mapping techniques assessing T1 relaxation times have allowed quantitative assessment of tissue composition and detection of both focal and diffuse interstitial myocardial fibrosis. T1 mapping performed before and after administration of gadolinium-based contrast media allows quantification of the extracellular volume (ECV), a surrogate measure for the extracellular space, which is expanded in myocardial fibrosis due to interstitial accumulation of collagen type I and III $(28,29)$.

Two CMR studies applying contrast enhancement techniques have revealed results consistent with increased myocardial fibrosis in PA, but only one applied a quantification technique for enhancement assessment $(30,31)$. One CMR study addressed the effect of medical mineralocorticoid receptor antagonist treatment in PA on cardiac volume overload and LV hypertrophy, with mineralocorticoid receptor antagonist treatment causing significant decreases in both LV mass and cardiac volumes (32). Further, CMR with T1 mapping has been used to evaluate the effect of HT and subsequent treatment with spironolactone on interstitial myocardial fibrosis in mice (33). Thus, the extent of fibrosis induced by PA and its reversibility is still incompletely known. We therefore aimed to assess myocardial mass and fibrosis in PA, using both dynamic contrast enhancement and T1 mapping, before and after adrenalectomy or medical treatment with mineralocorticoid receptor antagonist.

\section{Subjects and methods}

\section{Study participants and design}

This study was performed between October 2013 and March 2016 at Haukeland University Hospital, Bergen. Fifteen patients with recently confirmed PA (PA1) and 24 age- and sex-matched normotensive healthy subjects (HS) were included for baseline CMR with dynamic contrast enhancement (CMR1-CE) between October 2013 and June 2014 (Fig. 1). After completion of this substudy, they were invited to a follow-up CMR with T1 mapping (CMR2-T1, June 2015-March 2016), performed at least one year after the start of specific PA treatment. One patient was excluded from follow-up due to deterioration of renal function and four HS declined follow-up. An additional 17 newly diagnosed patients (PA2) were recruited of whom 16 completed the protocol.

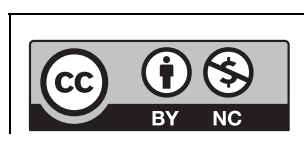

This work is licensed under a Creative Commons Attribution-NonCommercial 4.0 International License. 


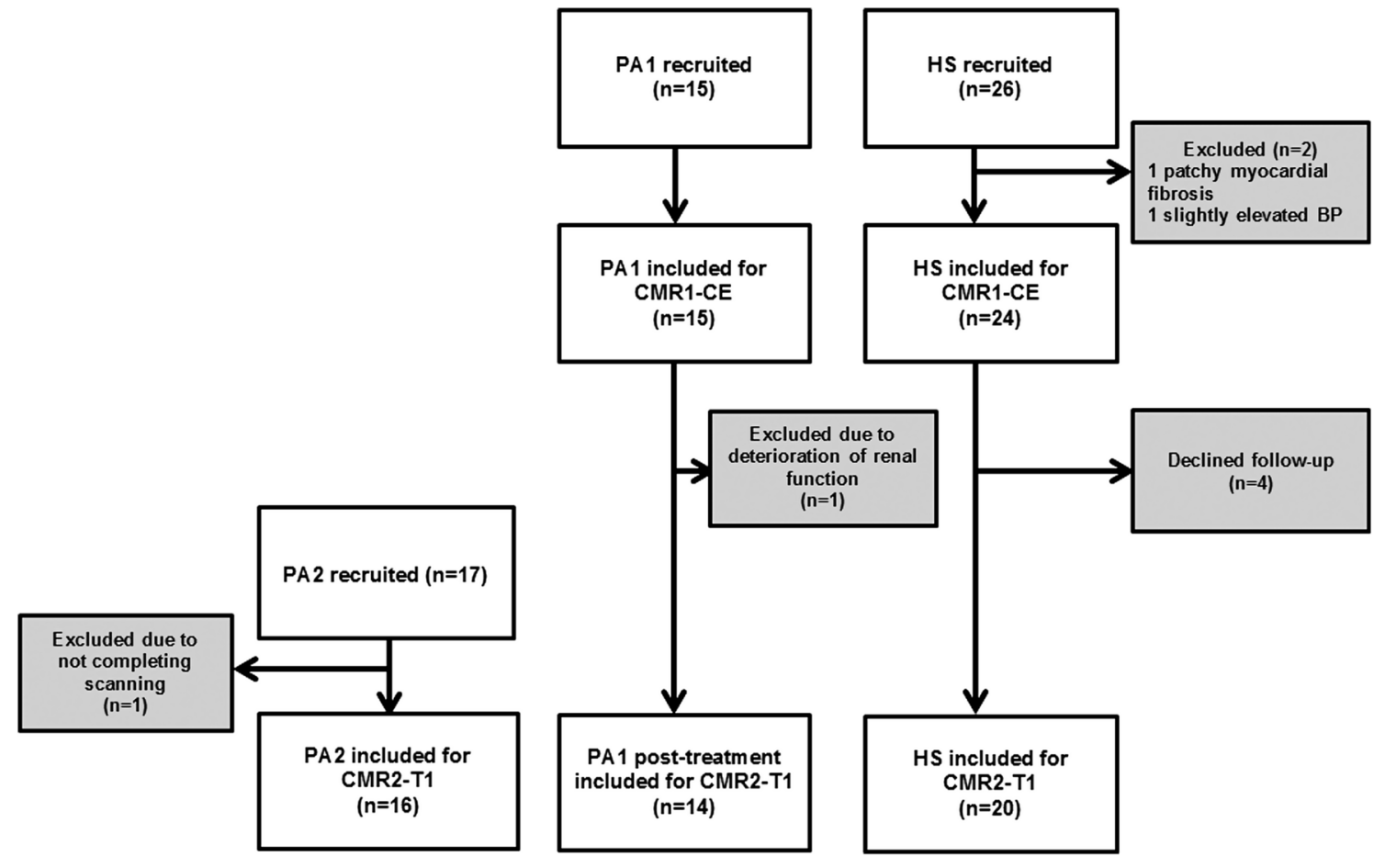

Figure 1

Study flow chart for the three study groups; PA1, HS and PA2. CMR1-CE, cardiac magnetic resonance imaging with dynamic contrast enhancement; CMR2-T1, cardiac magnetic resonance imaging with T1 mapping; HS, healthy subjects; PA1, primary aldosteronism group 1; PA2, primary aldosteronism group 2.

\section{Diagnosis and clinical assessment}

All PA patients had their diagnosis confirmed by saline infusion testing (SIT), and adrenal vein sampling (AVS) for subtype differentiation planned or performed at the time of study inclusion, according to current guidelines (4). Positive SIT was defined as a post-infusion plasma aldosterone level $>140 \mathrm{pmol} / \mathrm{L}(34,35)$. BP was measured in a standardized manner in all study groups, with three repetitive measurements in a seated position, after at least five minutes rest. Height and weight were recorded for all.

\section{CMR performed with dynamic contrast enhancement (CMR1-CE)}

PA1 and HS were examined with a 3T GE Signa Excite Scanner (Milwaukee, WI, USA). A phased-array cardiac coil with eight elements was used. All images were obtained during breath-hold with electrocardiography (ECG) triggering. For evaluation of LV mass and LV volumes, short-axis CINE views were obtained, using a Fiesta sequence. A pre-contrast mid-ventricular shortaxis view and a 4-chamber view were then performed before a gadolinium-based contrast agent (Gadovist $1 \mathrm{mmol} / \mathrm{mL}$, Bayer Pharma AG) $0.2 \mathrm{~mL} / \mathrm{kg}$ body weight

\begin{tabular}{lr}
\hline http://www.endocrineconnections.org & $\odot 2018$ The authors \\
https://doi.org/10.1530/EC-18-0039 & Published by Bioscientifica Ltd
\end{tabular}

was administered as an intravenous bolus injection. An inversion recovery gradient echo sequence was applied. Contrast images in the same views as pre-contrast were then acquired at seven consecutive time points $(2,4,6,8$, 10,12 and $14 \mathrm{~min}$ ) post-contrast.

\section{CMR performed with T1 mapping (CMR2-T1)}

The scanner used for the CMR1-CE was replaced in June 2014. The CMR2-T1 substudy was therefore performed with a 3T Siemens Magnetom Skyra (Erlangen, Germany). All images were obtained during breath-hold with ECG triggering. CINE views were performed using the same slice parameters as for the baseline CMR1-CE. The inversion recovery-based MOLLI sequence was used for T1 mapping (MyoMaps; Siemens, Erlangen) in accordance with the recommendations of the Society for Cardiovascular Magnetic Resonance (SMR) $(36,37)$. A native pre-contrast T1 mapping mid-ventricular short-axis view was then performed before the gadolinium-based contrast agent (Gadovist $1 \mathrm{mmol} / \mathrm{mL}$, Bayer Pharma AG) $0.15 \mathrm{~mL} / \mathrm{kg}$ body weight was administered as an intravenous bolus injection. Further T1 mapping mid-ventricular short-axis views were then performed 10, 15 and $20 \mathrm{~min}$ post-contrast.

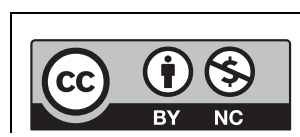

This work is licensed under a Creative Commons Attribution-NonCommercial 4.0 International License. 
ECG, oxygen saturation and pulse were monitored continuously during all CMR procedures. BP was measured regularly during all image sequences.

\section{Estimation of LV mass, volumes and function}

For estimation of LV mass, LV volumes and function, the CMR images were analysed by using the software Segment, version 1.9 R3697 (http://segment.heiberg.se) (38). End-diastole and end-systole were defined and LV endo- and epicardial borders were manually delineated in all slices in end-diastole and end-systole (excluding papillary muscles). Values for LV mass, LV end-diastolic volume (LV-EDV), end-systolic volume (LV-ESV), stroke volume (LV-SV), cardiac output (CO) and ejection fraction (EF) were then calculated, and mass and volumes were indexed to body surface area.

\section{Estimation of myocardial fibrosis from contrast enhancement images}

For the contrast enhancement image acquisition, a protocol earlier published by $\mathrm{Su}$ and coworkers was adopted and slightly modified (31). From mid-ventricular short-axis views performed pre- and at the different time points post-contrast, three non-overlapping regions of interest (ROI) were placed both in the interventricular septum and within the LV lumen (Fig. 2A). The average signal intensities (SI) both from the interventricular septum and the lumen were calculated. The contrast enhancement value was defined as the following ratio adopted from (31):

\section{Contrast enhancement value}

$$
=\frac{\text { SI post-contrast } \mathrm{myo}-\mathrm{SI} \text { native myo }}{\text { SI post-contrast blood }- \text { SI native blood }}
$$

SI post-contrast myo is the SI of myocardium after contrast, SI native myo is the SI of myocardium before contrast, SI post-contrast blood is the SI within the LV lumen after contrast and SI native blood is the SI within the lumen before contrast.

\section{Estimation of myocardial fibrosis from T1 mapping}

T1 mapping measurements were performed using syngo. via software (Siemens, Erlangen). One ROI covering most of the interventricular septum and one ROI within the LV lumen were drawn both from the native precontrast T1 mapping and the post-contrast T1 mapping
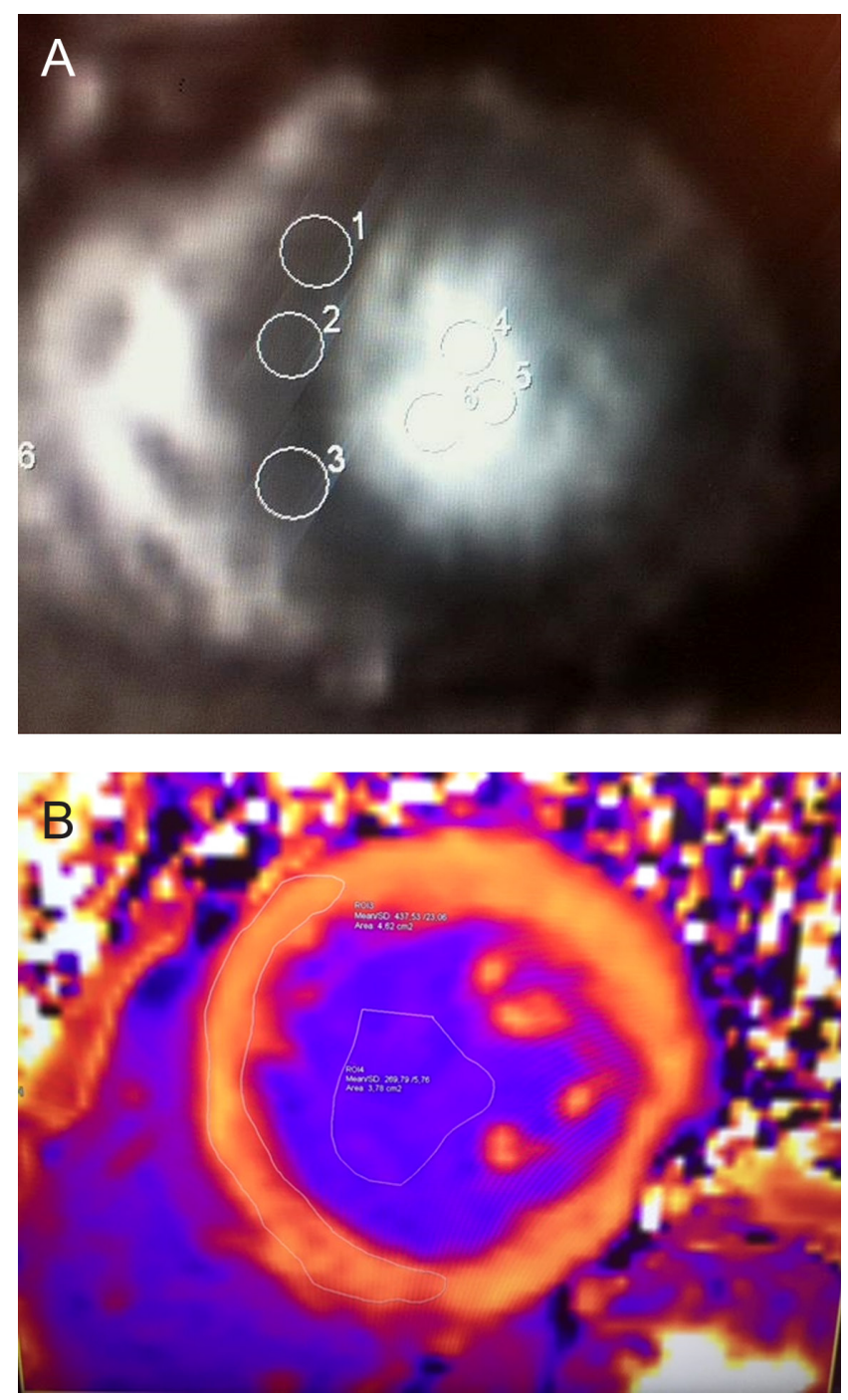

Figure 2

CMR imaging of the heart. (A) Post-contrast short-axis view of the heart with three ROIs drawn in the interventricular septum and lumen for calculation of contrast enhancement values (substudy CMR1-CE). (B) Post-contrast T1 mapping short-axis view of the heart with a ROI drawn in the interventricular septum and lumen for calculation of ECV (substudy CMR2-T1). CMR1-CE, cardiac magnetic resonance imaging with dynamic contrast enhancement; CMR2-T1, cardiac magnetic resonance imaging with T1 mapping; ECV, extracellular volume; ROI, region of interest.

short-axis views (Fig. 2B). The ECV was then calculated as a surrogate for the extracellular space using the following formula $(28,37)$ :

$$
\begin{aligned}
\text { ECV }(\%)= & \frac{\frac{1}{\text { T1 post-contrast myo }}-\frac{1}{\text { T1 native myo }}}{\frac{1}{\text { T1 post-contrast blood }}-\frac{1}{\text { T1 native blood }}} \\
& \times(100-\text { haematocrit })
\end{aligned}
$$

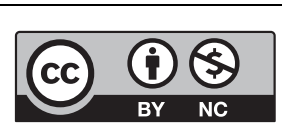

This work is licensed under a Creative Commons Attribution-NonCommercial 4.0 International License. 
T1 post-contrast myo is the SI of myocardium after contrast, T1 native myo is the SI of myocardium before contrast, T1 post-contrast blood is the SI within the LV lumen after contrast and T1 native blood is the SI within the lumen before contrast.

All post-processing measurements for both CMR1-CE and CMR2-T1 were performed by two investigators (MG/KS or MG/TL), and the mean values of the measurements from the two investigators were used for statistical analyses.

\section{Statistical analysis}

All parameters are expressed as median and ranges. Student's $t$-test and Mann-Whitney $U$ test were used to compare normally and not normally distributed continuous data between two groups, and Wilcoxon signed-rank test for within-patient not normally distributed data. One-way ANOVA was used to compare continuous data between more than two groups. For comparison of categorical variables, the chi-square test or Fisher's exact probability test was used. Bland-Altman plots were used for analysing the agreement between the measurements performed by the two investigators. A deviation of less than $10 \%$ between the values obtained by the two investigators was considered acceptable. $P$ values less than 0.05 were considered statistically significant.

Written informed consent was obtained from all participants. The study was approved by the Regional Committee for Medical and Health Research Ethics (REC West/University of Bergen).

\section{Results}

\section{Clinical characteristics: CMR with dynamic contrast enhancement (CMR1-CE)}

The clinical characteristics of PA1 and HS at the time of the baseline CMR1-CE are shown in Table 1. PA1 and HS did not differ in terms of age or sex, but the PA1 patients had higher body mass index (BMI) and higher BP than the HS (median BMI 26 (range 22-34) vs $23(18-27) \mathrm{kg} / \mathrm{m}^{2}$; $P<0.001$ and BP $138 / 90$ vs $118 / 75 \mathrm{mmHg} ; P<0.001$ for both systolic and diastolic BP).

In PA1, AVS performed for subtype differentiation showed unilateral PA in 9/15 patients, the remaining had bilateral (5/15) or not representative (1/15) AVS. Three PA1 patients had been adrenalectomized within the past three months prior to inclusion for CMR1-CE. Five had started medical mineralocorticoid receptor antagonist treatment within the past 4-7 months, while the remaining had not yet started specific PA treatment.

One patient in PA1 had established coronary disease at baseline (paroxysmal atrial fibrillation). One had experienced several cerebral infarctions before the age of 50 years. Two had diabetes mellitus type 2 , and two had chronic kidney disease, with estimated glomerular filtration rates of 47 and $54\left(\mathrm{~mL} / \mathrm{min} / 1.73 \mathrm{~m}^{2}\right)$ at baseline, respectively. One PA patient without a history of coronary disease had sequelae from a small cardiac infarction found on his CMR. He was referred for cardiac evaluation.

\section{Clinical characteristics: CMR with T1 mapping (CMR2-T1)}

For PA1, the CMR2-T1 was performed at least one year after the start of specific treatment either with unilateral adrenalectomy or medical treatment with mineralocorticoid receptor antagonists (Table 1). Eight of 14 PA1 patients had been adrenalectomized, with median 18 (range 12-21) months since adrenalectomy. The remaining 6/14 were on medical mineralocorticoid receptor antagonist treatment, with median 21 (12-27) months since start of this medication. BP at follow-up was still significantly higher in the PA1 than in the HS group (median BP $134 / 81$ vs $124 / 73 \mathrm{mmHg}$; systolic BP $P=0.02 /$ diastolic BP $P=0.012$ ), despite a median two antihypertensive drugs in the PA1 group. In PA1, only small non-significant BP changes appeared after treatment, with median systolic BP reduction $7 \mathrm{mmHg}$; $P=0.064$ and median diastolic $\mathrm{BP}$ reduction $5 \mathrm{mmHg}$; $P=0.148$ (not shown).

Among the 16 newly diagnosed patients in PA2 performing CMR2-T1, AVS showed unilateral disease in six patients and bilateral in 10 (Table 1). Only one of the newly diagnosed PA patients in PA2 had started specific PA treatment with spironolactone two months before the CMR2-T1; none in PA2 had yet been adrenalectomized. One of the PA2 patients had ischaemic coronary disease treated with percutaneous coronary intervention as comorbidity, two had atrial fibrillation (one paroxysmal and one radiofrequency ablated), and one had diabetes mellitus type 1 . Median BP was $145 / 91 \mathrm{mmHg}$ in PA2, with median three (0-6) antihypertensive drugs.

\section{LV function and LV mass: CMR with dynamic contrast enhancement (CMR1-CE)}

The results from LV function and LV mass measured with CMR1-CE are listed in Table 2. Baseline LV mass

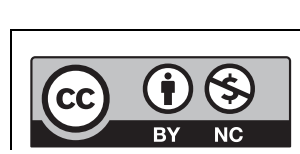

This work is licensed under a Creative Commons Attribution-NonCommercial 4.0 International License. 
Table 1 Clinical and biochemical characteristics of PA1, HS and PA2 at substudy CMR1-CE and substudy CMR2-T1.*

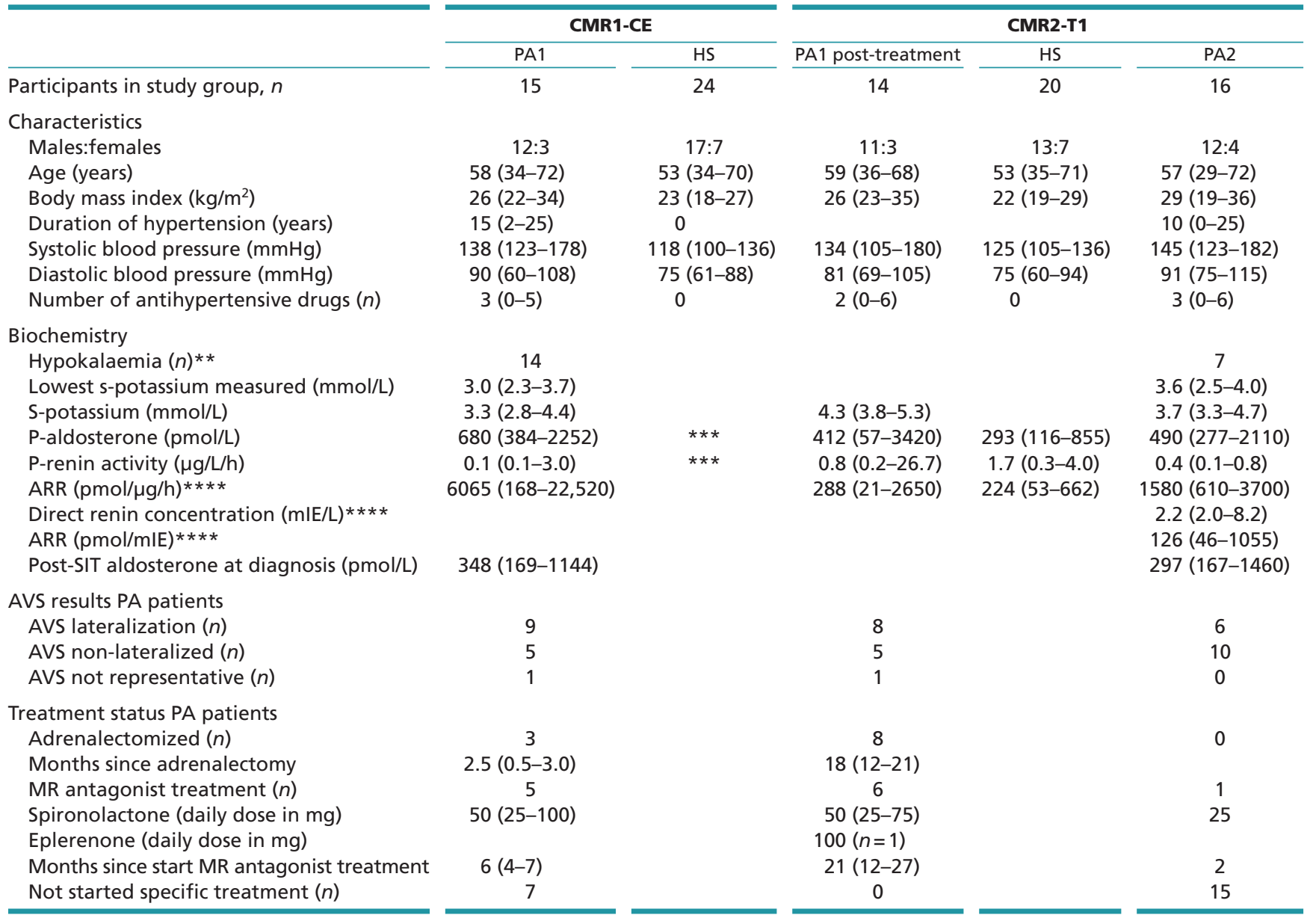

*Data shown as median (range) or as number; **hypokalaemia was defined as s-potassium $<3.5 \mathrm{mmol} / \mathrm{L}$ at least once; ***p-aldosterone and p-renin activity in the healthy subjects (HS) were measured at the time of the CMR2-T1; ****ARR calculated with plasma renin activity: normal range $<750$ pmol/ $\mu \mathrm{g} / \mathrm{h}$. The renin assay was in February 2016 changed from plasma renin activity (Gammacoat, Diasorin) to direct renin concentration (LIAISON Direct Renin, DiaSorin). 7/16 of the patients in the PA2 group therefore had their renin measured as direct renin concentration. ARR calculated with direct renin concentration: normal range $<50 \mathrm{pmol} / \mathrm{mlE}$ with aldosterone $<300 \mathrm{pmol} / \mathrm{L}$, normal range $<35 \mathrm{pmol} / \mathrm{mIE}$ with aldosterone $>300 \mathrm{pmol} / \mathrm{L}$. ARR, aldosterone-renin ratio; AVS, adrenal vein sampling; CMR1-CE, cardiac magnetic resonance imaging with dynamic contrast enhancement; CMR2-T1, cardiac magnetic resonance imaging with T1 mapping; HS, healthy subjects; MR antagonist, mineralocorticoid receptor antagonist; PA1, primary aldosteronism group 1; PA2, primary aldosteronism group 2; SIT, saline infusion test.

indexed to body surface area differed significantly between the PA1 and HS group (LV mass index 69 (53-91) vs $\left.51(40-72) \mathrm{g} / \mathrm{m}^{2} ; P<0.001\right)$. No differences between the two groups were found in cardiac function measured as LV-EDV index, LV-ESV index, LV-SV index, LV-EF, HR or CO index.

\section{Dynamic contrast enhancement results (CMR1-CE)}

Figure 3 illustrates the contrast enhancement values in PA1 and HS measured from 2 to $14 \mathrm{~min}$ post-contrast. No difference was found in contrast enhancement value between PA1 and HS at any time point. For both PA1 and
HS, the contrast enhancement showed a trend towards reduced values from 2 to $14 \mathrm{~min}$ post-contrast.

\section{LV function and LV mass-CMR with T1 mapping (CMR2-T1)}

LV function and LV mass indexes for PA1, HS and PA2 measured with CMR2-T1 are shown in Table 2. At follow-up CMR2-T1, PA1 had a significantly reduced LV mass index (LV mass index $58(40-86) \mathrm{g} / \mathrm{m}^{2} ; P<0.001$ vs baseline values). LV mass index in PA1 was still higher, but no longer significantly different to LV mass index in HS (LV mass index 58 (40-86) vs $57(45-75) \mathrm{g} / \mathrm{m}^{2}$; $P=\mathrm{ns})$. When analysing the adrenalectomized $(n=8)$

$$
\begin{array}{lr}
\text { http://www.endocrineconnections.org } & \text { ○ } 2018 \text { The authors } \\
\text { https://doi.org/10.1530/EC-18-0039 } & \text { Published by Bioscientifica Ltd }
\end{array}
$$


Table 2 CMR left ventricular parameters for PA1, HS and PA2 at substudy CMR1-CE and substudy CMR2-T1.*

\begin{tabular}{|c|c|c|c|c|c|c|c|}
\hline & CMR & 1-CE & & CMR2-T1 & & & $\begin{array}{c}P \text { value PA1 } \\
\text { post-treatment }\end{array}$ \\
\hline & PA1 $(n=15)$ & $\mathrm{HS}(n=24)$ & $\begin{array}{l}\text { PA1 post-treatment } \\
\qquad(n=14)\end{array}$ & HS $(n=20)$ & $\mathrm{PA} 2(n=16)$ & $\begin{array}{c}\text { vs HS } \\
(\text { CMR1-CE)* * }\end{array}$ & $\begin{array}{c}\text { baseline } \\
\text { (CMR1-CE)* * }\end{array}$ \\
\hline LV-EDV index $\left(\mathrm{mL} / \mathrm{m}^{2}\right)$ & 85 (72-109) & $91(62-120)$ & $79(61-104)$ & $91(76-121)$ & 97 (69-116) & ns & ns \\
\hline LV-ESV index $\left(\mathrm{mL} / \mathrm{m}^{2}\right)$ & $33(20-52)$ & $37(24-51)$ & $31(20-47)$ & $37(23-54)$ & $38(19-51)$ & ns & ns \\
\hline LV-SV index $\left(\mathrm{mL} / \mathrm{m}^{2}\right)$ & $53(33-68)$ & $53(38-73)$ & $48(33-66)$ & $53(36-72)$ & $57(49-86)$ & ns & ns \\
\hline LV-EF (\%) & $62(45-74)$ & $62(52-67)$ & $60(48-73)$ & $60(42-71)$ & $62(51-74)$ & ns & ns \\
\hline HR (beats/min) & $64(39-87)$ & $66(50-84)$ & $63(44-80)$ & $53(38-66)$ & $54(42-68)$ & ns & ns \\
\hline $\mathrm{CO}$ index $\left(\mathrm{L} / \mathrm{min} / \mathrm{m}^{2}\right)$ & $3.5(2.2-4.4)$ & $3.5(2.3-5.0)$ & $2.6(2.0-4.5)$ & $3.0(1.9-4.0)$ & $3.1(2.0-4.8)$ & ns & ns \\
\hline LV mass index $\left(\mathrm{g} / \mathrm{m}^{2}\right)$ & $69(53-91)$ & $51(40-72)$ & $58(40-86)$ & $57(45-75)$ & $70(50-92)$ & $<0.001$ & $<0.001$ \\
\hline
\end{tabular}

*Data shown as median (range); **Student's $t$-test used.

$\mathrm{CO}$, cardiac output; CMR, cardiac magnetic resonance imaging; CMR1-CE, cardiac magnetic resonance imaging with dynamic contrast enhancement; CMR2-T1, cardiac magnetic resonance imaging with T1 mapping; EDV, end-diastolic volume; EF, ejection fraction; ESV, end-systolic volume; HS, healthy subjects; LV, left ventricular; PA1, primary aldosteronism group 1; PA2, primary aldosteronism group 2; SV, stroke volume.

and the medically treated $(n=6)$ PA1 patients separately, the adrenalectomized patients had a larger and highly significant reduction of LV mass index, compared with the medically treated patients who showed a trend towards, but had no significant reduction in LV mass index (adrenalectomized PA1 median reduction of LV mass

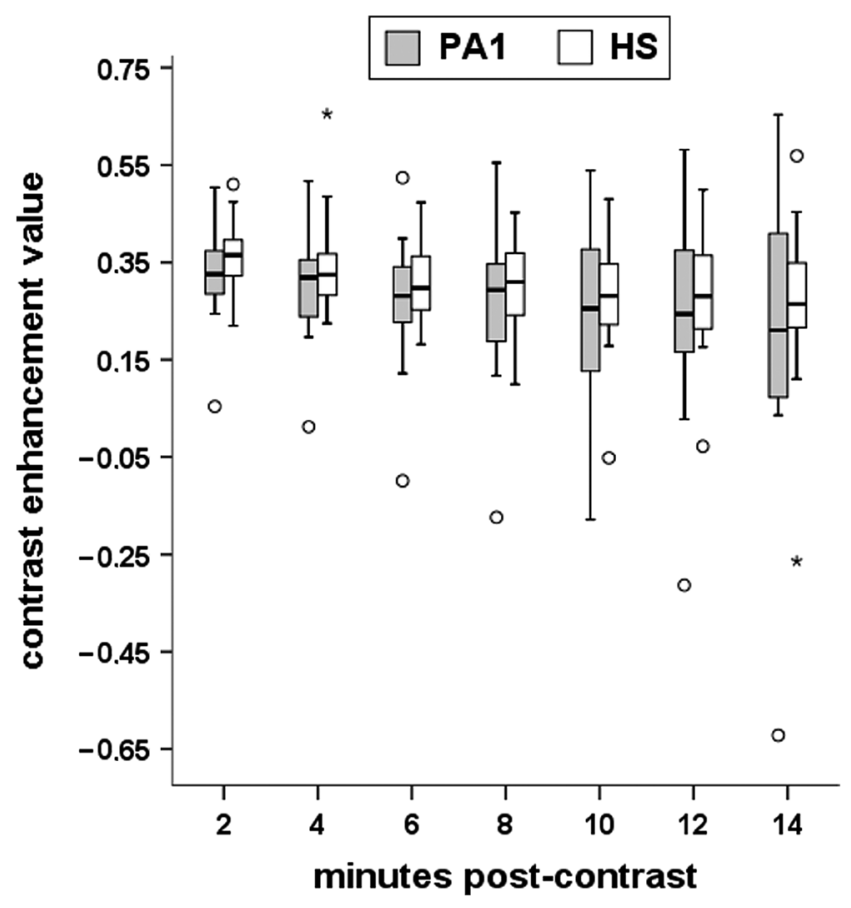

Figure 3

Box plots of dynamic contrast enhancement distribution at 2-14 min post-contrast for PA1 and HS (substudy CMR1-CE). The horizontal line indicates the median, the box represents the 25th-75th percentiles, and the whiskers represent the minimum and maximum value. Circles and asterisk indicate outliers. CMR1-CE, cardiac magnetic resonance imaging with dynamic contrast enhancement; HS, healthy subjects; PA1, primary aldosteronism group 1.

$$
\begin{aligned}
& \text { http://www.endocrineconnections.org } \\
& \text { https://doi.org/10.1530/EC-18-0039 }
\end{aligned}
$$

C) 2018 The authors Published by Bioscientifica Ltd index $-9 \mathrm{~g} / \mathrm{m}^{2} ; P=0.003$ vs mineralocorticoid receptor antagonist treated PA1 reduction of $L V$ mass index $-5 \mathrm{~g} / \mathrm{m}^{2}$; $P=0.075$, not shown).

The newly diagnosed PA2 group had significantly higher LV mass index at CMR2-T1 than both the treated PA1 and HS (PA2 median LV mass index 70 (50-92); $P=0.019$ vs treated PA1; PA2 vs HS $P<0.001)$.

For PA1, LV-EDV index showed a non-significant trend of reduction from baseline CMR1-CE to follow-up CMR2-T1 $(P=0.076)$. In the HS group, LV-EDV remained unchanged (Table 2). When comparing the adrenalectomized vs medically mineralocorticoid receptor antagonist-treated PA patients, only the PA1 patients treated with mineralocorticoid receptor antagonists had a significant reduction in LV-EDV index (medically treated PA1 median change in LV-EDV index $-14 \mathrm{~mL} / \mathrm{m}^{2} ; P=0.03$, vs adrenalectomized PA1 $-7 \mathrm{~mL} / \mathrm{m}^{2} ; P=0.54$ (not shown)).

\section{T1 mapping results (CMR2-T1)}

The results from the T1 mapping performed with CMR2-T1 for both treated PA1, newly diagnosed PA2 and HS are shown in Fig. 4. No increase in ECV as a CMR marker of interstitial fibrosis was found in either PA1 or PA2 compared with HS. On the contrary, ECV was significantly lower in the untreated PA2 than in the HS 10 min post-contrast, and in both PA groups compared with the HS group 20 min post-contrast. No significant difference in ECV was found between PA1 and PA2 at any time-point post-contrast.

\section{Discussion}

In this study, we applied CMR to explore the effects of PA, before and after treatment, on myocardial morphology

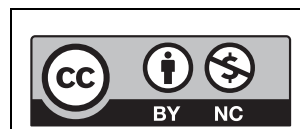

This work is licensed under a Creative Commons Attribution-NonCommercial 4.0 International License. 


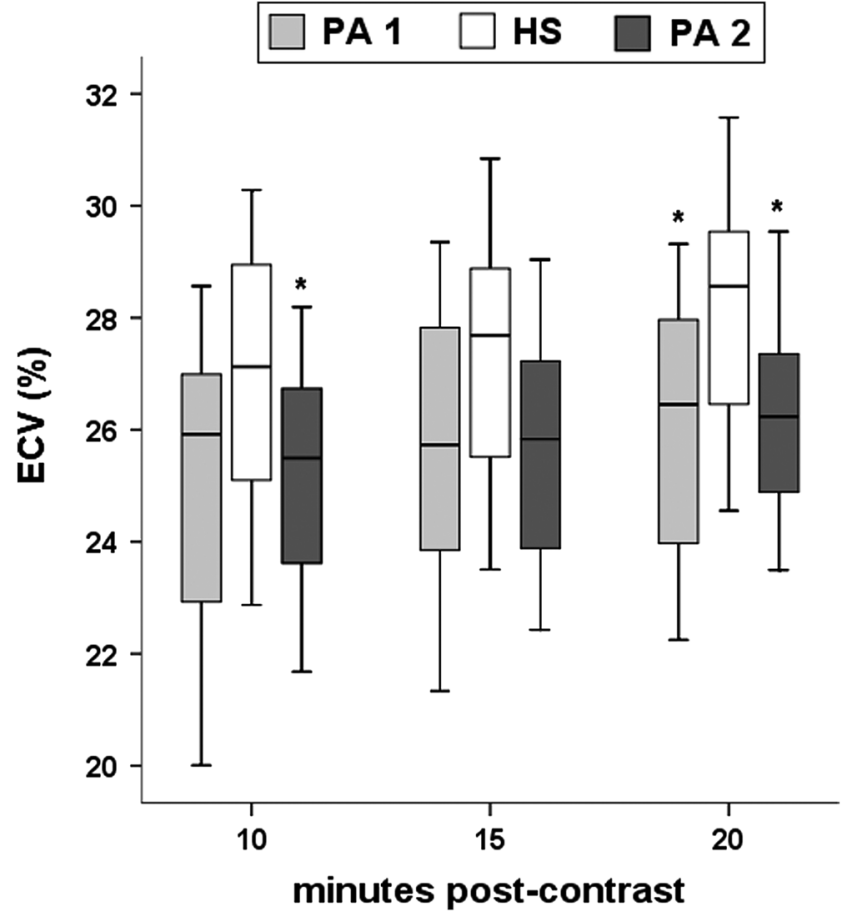

Figure 4

Box plots of the ECV distribution from T1 mapping at 10, 15 and $20 \mathrm{~min}$ post-contrast for PA1 (post-treatment), PA2 (newly diagnosed) and HS (substudy CMR2-T1). The horizontal line indicates the median, the box represents the 25 th-75th percentiles, and the whiskers represent the minimum and maximum value. ${ }^{*} P<0.05$ vs HS. CMR2-T1, cardiac magnetic resonance imaging with T1 mapping; ECV, extracellular volume; HS, healthy subjects; PA1, primary aldosteronism group 1; PA2, primary aldosteronism group 2.

and function. The myocardial hypertrophy observed at diagnosis rapidly normalized with treatment, most pronounced after adrenalectomy. However, surprisingly neither dynamic contrast enhancement nor T1 mapping revealed myocardial fibrosis in newly diagnosed PA compared with HS.

The finding of lack of increased myocardial fibrosis in PA contrasts both earlier experimental studies and human ultrasonographic backscatter signal and videodensitometric studies $(12,13,17,18,19)$. However, $\mathrm{CMR}$ is the recommended imaging modality for myocardial tissue characterization, and our findings also contrast two former 1.5 Tesla CMR studies using contrast enhancement techniques, which both showed higher contrast enhancement in PA than in essential hypertensive patients and healthy controls $(30,31)$. However, in one of these studies (30), contrast enhancement was measured as the presence of a non-infarct diffuse pattern of LGE, which is a less objective method to evaluate diffuse myocardial fibrosis (28). The other study used the same formula for dynamic contrast enhancement as we (31).
However, there is still no universally accepted optimal dynamic contrast enhancement quantification technique, which may be reflected in the discrepancy of our results despite applying the same technique $(28,39)$. The PA patients in the two former studies were slightly younger than both our PA groups, but had a similar duration of HT. Possible differences in PA subtypes, severity of PA phenotype, gender distribution or severity of HT might also have influenced our discrepant results.

The recent developments of $\mathrm{T} 1$ mapping techniques enable quantitative assessments of changes in myocardial tissue composition and the presence of diffuse myocardial fibrosis, with estimation of the ECV percentage. T1 mapping thus facilitates a non-invasive alternative to myocardial biopsies and histochemical analyses (40). If myocardial fibrosis is present, expansion of the extracellular interstitial space should yield higher ECV. ECV has been shown to correlate well with histological fibrosis in several cardiac diseases (28), and this is the first time this technique is used to study PA. Similar to dynamic contrast enhancement, T1 mapping showed no evidence of increased myocardial fibrosis. In contrast, we found that both the newly diagnosed and treated PA group in our study had, at $20 \mathrm{~min}$ post-contrast, lower ECV than the healthy subjects. Thus, the left ventricular intracellular fraction is increased, which indicates more pronounced cardiomyocyte hypertrophy than ECV increase in both PA groups. Our findings clearly challenge the widely held conception that substantial myocardial fibrosis is typical in PA. Myocardial interstitial fibrosis caused by aldosterone and salt loading has been histologically proven in experimental animal studies (12, $41,42)$. Human myocardial fibroblasts may differ from rodents when exposed to excess amounts of aldosterone, and the experimental levels of aldosterone and sodium in rodents may not reflect the exposure in humans with PA. To our knowledge, only one small human post-mortem study of five patients of high age with adrenal adenomas with suspected PA due to concomitant HT and low or lownormal s-potassium levels has been performed. That study showed histological fibrosis both in the myocardium as well as in the pancreas and lungs (43). However, ageing is associated with progressive fibrosis (44), and in the former study, the patients were approximately ten years older than in our study. Moreover, significant fibrosis may well be an end stage of long-standing and untreated PA. Furthermore, the fact that risks of cardiovascular complications in untreated PA are reduced to the same level as in essential HT after specific PA treatment, supports that irreversible fibrosis is not present (20). Essentially, this is the first study

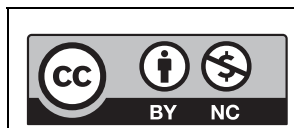

This work is licensed under a Creative Commons Attribution-NonCommercial 4.0 International License. 
to apply CMR T1 mapping with quantitative assessment of $\mathrm{ECV}$, which is the recommended gold standard parametric mapping technique for evaluation of diffuse myocardial fibrosis in a newly published consensus statement (37).

We also measured the effect of PA treatment on LV mass index and found a significant reduction after treatment. Regression of LV hypertrophy is associated with improved cardiovascular outcome in essential HT (45). When analysing the adrenalectomized and medically treated PA patients separately, reduction of LV mass index was highly significant only for the adrenalectomized group. Although not significant, we observed a strong trend towards reduction of LV mass index also in the medically treated group, with a median follow-up time of less than two years. These findings are in accordance with another CMR study, which showed significant regression of LV mass index in patients with suspected PA both after 3and 6-month treatment with mineralocorticoid receptor antagonists (32). One echocardiographic study showed no significant change of LV mass index one year after start of mineralocorticoid receptor antagonist treatment, whereas another large study showed borderline significant reduction in $\mathrm{LV}$ mass index in medically treated PA after a median follow-up of 36 months $(21,22)$. The regression in LV mass after specific PA treatment occurred despite no significant reduction in BP. In the Framingham Offspring study, the aldosterone-to-renin ratio was identified as a key correlate of LV hypertrophy (46). Studies conducted in patients with essential HT have similarly shown a direct relationship between aldosterone levels and changes in LV geometry $(47,48)$. Thus, the reduction of LV mass after PA treatment is probably due to both reduced aldosterone levels and improved BP.

In the PA patients, we found a significant reduction in LV-EDV index only in the medically treated subgroup, in accordance with a former study (32). PA is associated with increased plasma brain natriuretic peptide and intracardiac volume overload, which is reversed by mineralocorticoid receptor antagonists or adrenalectomy. In the former study, the intracardiac volume overload was refractory to thiazides, while low doses of spironolactone showed a prominent diuretic effect. Small numbers may explain why no difference was found in LV-EDV index in the adrenalectomized patients in the current study.

A limitation of our study is that not all PA1 patients were completely treatment naive at the time of the CMR1-CE; some had already undergone adrenalectomy and some had commenced treatment with mineralocorticoid receptor antagonists shortly before. Among the newly diagnosed PA2 patients participating in the CMR2-T1, only one patient had started specific PA treatment shortly before his CMR. PA patients with unilateral disease often have a more florid phenotype, and the relatively large proportion of patients with bilateral disease in PA2 may represent a less severe form of PA, which may have influenced the T1 mapping results.

The lack of an additional hypertensive control group is a limitation. If evidence of increased myocardial fibrosis in PA compared with in healthy subjects had been found, such a control group would have been necessary to determine whether these changes were caused by aldosterone excess or haemodynamic effects of hypertension itself. Furthermore, it could have shown whether the lower ECV in both treated and untreated PA post-contrast would be caused by aldosterone or haemodynamic effects of hypertension per se.

The replacement of the CMR scanner used at baseline with a new scanner for the follow-up CMR2-T1, may pose a further limitation. On the other hand, the use of two different techniques to study myocardial fibrosis with overlapping results certainly strengthens the study. A further asset is that all post-image analyses were performed by two different investigators. A limitation is that the dynamic contrast enhancement technique and T1 mapping were applied at different time points of the study, and we were therefore unable to examine the study participants with these two methods simultaneously, which would have given direct comparisons of the two methods. The PA1 patients had all received specific PA treatment for at least a year when examined with T1 mapping but were relatively treatment naïve when examined with dynamic contrast enhancement, which precludes direct comparisons of contrast enhancement and T1 mapping results in this group. In order to examine treatment-naïve PA patients with T1mapping, we therefore included also the newly diagnosed PA2 group for the CMR2-T1.

Habitual dietary sodium intake of the study participants was not recorded, and it is unknown whether the PA patients had been given specific dietary counselling to reduce their salt intake prior to or during the study period. In experimental animal studies, high levels of aldosterone infusion did not cause cardiovascular damage when sodium intake was very low (12). Similarly, in humans, extraordinarily high aldosterone concentrations in populations with chronic sodium deficiency was not associated with cardiovascular damage (49). A recent study demonstrated that dietary salt intake influenced the reduction of LV mass after PA treatment (50). Thus, dietary sodium intake may have influenced our results. http://www.endocrineconnections.org https://doi.org/10.1530/EC-18-0039
() 2018 The authors Published by Bioscientifica Ltd

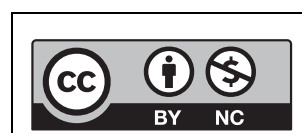

This work is licensed under a Creative Commons Attribution-NonCommercial 4.0 International License. 
In conclusion, specific PA treatment rapidly reduced LV mass. Both dynamic contrast enhancement and, notably, the recommended T1 mapping, showed no evidence of increased myocardial fibrosis in PA patients compared with healthy individuals. Thus, myocardial fibrosis does not seem to be a significant clinical problem in PA if diagnosed and treated within time frames commonly used in clinical practice.

\section{Declaration of interest}

The authors declare that there is no conflict of interest that could be perceived as prejudicing the impartiality of the research reported.

\section{Funding}

This study was supported by the Regional Health Authorities in Western Norway.

\section{Acknowledgements}

The authors are very grateful to the participating patients and controls for their cooperation. They thank Jarle B Seter, Merete S Lemme, Anne Marie Kira, Jan A Monssen and Christel Jansen for their expert technical assistance.

\section{References}

1 Rossi GP, Bernini G, Caliumi C, Desideri G, Fabris B, Ferri C, Ganzaroli C, Giacchetti G, Letizia C, Maccario M, et al. A prospective study of the prevalence of primary aldosteronism in 1,125 hypertensive patients. Journal of the American College of Cardiology 200648 2293-2300. (https://doi.org/10.1016/j.jacc.2006.07.059)

2 Jansen PM, Boomsma F, van den Meiracker AH \& Dutch AI. Aldosterone-to-renin ratio as a screening test for primary aldosteronism - the Dutch ARRAT Study. Netherlands Journal of Medicine $200866220-228$.

3 Nishizaka MK, Pratt-Ubunama M, Zaman MA, Cofield S \& Calhoun DA. Validity of plasma aldosterone-to-renin activity ratio in African American and white subjects with resistant hypertension. American Journal of Hypertension 200518 805-812. (https://doi. org/10.1016/j.amjhyper.2005.01.002)

4 Funder JW, Carey RM, Mantero F, Murad MH, Reincke M, Shibata H, Stowasser M \& Young WF Jr. The management of primary aldosteronism: case detection, diagnosis, and treatment: an Endocrine Society Clinical Practice Guideline. Journal of Clinical Endocrinology and Metabolism 2016101 1889-1916. (https://doi. org/10.1210/jc.2015-4061)

5 Milliez P, Girerd X, Plouin PF, Blacher J, Safar ME \& Mourad JJ. Evidence for an increased rate of cardiovascular events in patients with primary aldosteronism. Journal of the American College of Cardiology 200545 1243-1248. (https://doi.org/10.1016/j. jacc.2005.01.015)

6 Born-Frontsberg E, Reincke M, Rump LC, Hahner S, Diederich S, Lorenz R, Allolio B, Seufert J, Schirpenbach C, Beuschlein F, et al. Cardiovascular and cerebrovascular comorbidities of hypokalemic and normokalemic primary aldosteronism: results of the German Conn's Registry. Journal of Clinical Endocrinology and Metabolism 2009 94 1125-1130. (https://doi.org/10.1210/jc.2008-2116)

7 Rossi GP, Bernini G, Desideri G, Fabris B, Ferri C, Giacchetti G, Letizia C, Maccario M, Mannelli M, Matterello MJ, et al. Renal damage in primary aldosteronism: results of the PAPY Study. Hypertension 200648 232-238. (https://doi.org/10.1161/01. HYP.0000230444.01215.6a)

8 Mulatero P, Monticone S, Bertello C, Viola A, Tizzani D, Iannaccone A, Crudo V, Burrello J, Milan A, Rabbia F, et al. Longterm cardio- and cerebrovascular events in patients with primary aldosteronism. Journal of Clinical Endocrinology and Metabolism 2013 98 4826-4833. (https://doi.org/10.1210/jc.2013-2805)

9 Reincke M, Fischer E, Gerum S, Merkle K, Schulz S, Pallauf A, Quinkler M, Hanslik G, Lang K, Hahner S, et al. Observational study mortality in treated primary aldosteronism: the German Conn's registry. Hypertension 201260 618-624. (https://doi.org/10.1161/ HYPERTENSIONAHA.112.197111)

10 Hanslik G, Wallaschofski H, Dietz A, Riester A, Reincke M, Allolio B, Lang K, Quack I, Rump LC, Willenberg HS, et al. Increased prevalence of diabetes mellitus and the metabolic syndrome in patients with primary aldosteronism of the German Conn's Registry. European Journal of Endocrinology 2015173 665-675. (https://doi.org/10.1530/ EJE-15-0450)

11 Arlt W, Lang K, Sitch AJ, Dietz AS, Rhayem Y, Bancos I, Feuchtinger A, Chortis V, Gilligan LC, Ludwig P, et al. Steroid metabolome analysis reveals prevalent glucocorticoid excess in primary aldosteronism. JCI Insight 20172 93136. (https://doi. org/10.1172/jci.insight.93136)

12 Brilla CG \& Weber KT. Mineralocorticoid excess, dietary sodium, and myocardial fibrosis. Journal of Laboratory and Clinical Medicine 1992 120 893-901.

13 Young M, Fullerton M, Dilley R \& Funder J. Mineralocorticoids, hypertension, and cardiac fibrosis. Journal of Clinical Investigation 199493 2578-2583. (https://doi.org/10.1172/JCI117269)

14 Sun Y, Zhang J, Lu L, Chen SS, Quinn MT \& Weber KT. Aldosteroneinduced inflammation in the rat heart: role of oxidative stress. American Journal of Pathology 2002161 1773-1781. (https://doi. org/10.1016/S0002-9440(10)64454-9)

15 Rocha R, Stier CT Jr, Kifor I, Ochoa-Maya MR, Rennke HG, Williams GH \& Adler GK. Aldosterone: a mediator of myocardial necrosis and renal arteriopathy. Endocrinology 2000141 3871-3878. (https://doi.org/10.1210/endo.141.10.7711)

16 Rossi GP, Sacchetto A, Visentin P, Canali C, Graniero GR, Palatini P $\&$ Pessina AC. Changes in left ventricular anatomy and function in hypertension and primary aldosteronism. Hypertension 199627 1039-1045. (https://doi.org/10.1161/01.HYP.27.5.1039)

17 Rossi GP, Di Bello V, Ganzaroli C, Sacchetto A, Cesari M, Bertini A, Giorgi D, Scognamiglio R, Mariani M \& Pessina AC. Excess aldosterone is associated with alterations of myocardial texture in primary aldosteronism. Hypertension 200240 23-27. (https://doi. org/10.1161/01.HYP.0000023182.68420.EB)

18 Kozakova M, Buralli S, Palombo C, Bernini G, Moretti A, Favilla S, Taddei S \& Salvetti A. Myocardial ultrasonic backscatter in hypertension: relation to aldosterone and endothelin. Hypertension 200341 230-236. (https://doi.org/10.1161/01. HYP.0000052542.68896.2B)

19 Lee HH, Hung CS, Wu XM, Wu VC, Liu KL, Wang SM, Lin LC, Chen PC, Guo YL, Chueh SC, et al. Myocardial ultrasound tissue characterization of patients with primary aldosteronism. Ultrasound in Medicine and Biology 201339 54-61. (https://doi.org/10.1016/j. ultrasmedbio.2012.08.023)

20 Catena C, Colussi G, Nadalini E, Chiuch A, Baroselli S, Lapenna R $\&$ Sechi LA. Cardiovascular outcomes in patients with primary aldosteronism after treatment. Archives of Internal Medicine 2008168 80-85. (https://doi.org/10.1001/archinternmed.2007.33)

21 Catena C, Colussi G, Lapenna R, Nadalini E, Chiuch A, Gianfagna P $\&$ Sechi LA. Long-term cardiac effects of adrenalectomy or mineralocorticoid antagonists in patients with primary aldosteronism. Hypertension 200750 911-918. (https://doi. org/10.1161/HYPERTENSIONAHA.107.095448) 
22 Rossi GP, Cesari M, Cuspidi C, Maiolino G, Cicala MV, Bisogni V, Mantero F \& Pessina AC. Long-term control of arterial hypertension and regression of left ventricular hypertrophy with treatment of primary aldosteronism. Hypertension 201362 62-69. (https://doi. org/10.1161/HYPERTENSIONAHA.113.01316)

23 Marzano L, Colussi G, Sechi LA \& Catena C. Adrenalectomy is comparable with medical treatment for reduction of left ventricular mass in primary aldosteronism: meta-analysis of long-term studies. American Journal of Hypertension 201428 312-318. (https://doi. org/10.1093/ajh/hpu154)

24 Kim RJ, Fieno DS, Parrish TB, Harris K, Chen EL, Simonetti O, Bundy J, Finn JP, Klocke FJ \& Judd RM. Relationship of MRI delayed contrast enhancement to irreversible injury, infarct age, and contractile function. Circulation 1999100 1992-2002.

25 Choudhury L, Mahrholdt H, Wagner A, Choi KM, Elliott MD, Klocke FJ, Bonow RO, Judd RM \& Kim RJ. Myocardial scarring in asymptomatic or mildly symptomatic patients with hypertrophic cardiomyopathy. Journal of the American College of Cardiology 200240 2156-2164. (https://doi.org/10.1016/S07351097(02)02602-5)

26 Wu E, Ortiz JT, Tejedor P, Lee DC, Bucciarelli-Ducci C, Kansal P, Carr JC, Holly TA, Lloyd-Jones D, Klocke FJ, et al. Infarct size by contrast enhanced cardiac magnetic resonance is a stronger predictor of outcomes than left ventricular ejection fraction or end-systolic volume index: prospective cohort study. Heart 200894 730-736. (https://doi.org/10.1136/hrt.2007.122622)

27 Rubinshtein R, Glockner JF, Ommen SR, Araoz PA, Ackerman MJ, Sorajja P, Bos JM, Tajik AJ, Valeti US, Nishimura RA, et al. Characteristics and clinical significance of late gadolinium enhancement by contrast-enhanced magnetic resonance imaging in patients with hypertrophic cardiomyopathy. Circulation: Heart Failure 20103 51-58. (https://doi.org/10.1161/ CIRCHEARTFAILURE.109.854026)

28 Everett RJ, Stirrat CG, Semple SI, Newby DE, Dweck MR \& Mirsadraee S. Assessment of myocardial fibrosis with T1 mapping MRI. Clinical Radiology 201671 768-778. (https://doi.org/10.1016/j. crad.2016.02.013)

29 Miller CA, Naish JH, Bishop P, Coutts G, Clark D, Zhao S, Ray SG, Yonan N, Williams SG, Flett AS, et al. Comprehensive validation of cardiovascular magnetic resonance techniques for the assessment of myocardial extracellular volume. Circulation: Cardiovascular Imaging 20136 373-383. (https://doi.org/10.1161/ CIRCIMAGING.112.000192)

30 Freel EM, Mark PB, Weir RA, McQuarrie EP, Allan K, Dargie HJ, McClure JD, Jardine AG, Davies E \& Connell JM. Demonstration of blood pressure-independent noninfarct myocardial fibrosis in primary aldosteronism: a cardiac magnetic resonance imaging study. Circulation: Cardiovascular Imaging 20125 740-747. (https://doi. org/10.1161/CIRCIMAGING.112.974576)

31 Su MY, Wu VC, Yu HY, Lin YH, Kuo CC, Liu KL, Wang SM, Chueh SC, Lin LY, Wu KD, et al. Contrast-enhanced MRI index of diffuse myocardial fibrosis is increased in primary aldosteronism. Journal of Magnetic Resonance Imaging 201235 1349-1355. (https:// doi.org/10.1002/jmri.23592)

32 Gaddam K, Corros C, Pimenta E, Ahmed M, Denney T, Aban I, Inusah S, Gupta H, Lloyd SG, Oparil S, et al. Rapid reversal of left ventricular hypertrophy and intracardiac volume overload in patients with resistant hypertension and hyperaldosteronism: a prospective clinical study. Hypertension 201055 1137-1142. (https:// doi.org/10.1161/HYPERTENSIONAHA.109.141531)

33 Coelho-Filho OR, Shah RV, Neilan TG, Mitchell R, Moreno H Jr, Kwong R \& Jerosch-Herold M. Cardiac magnetic resonance assessment of interstitial myocardial fibrosis and cardiomyocyte hypertrophy in hypertensive mice treated with spironolactone. Journal of the American Heart Association 20143 e000790. (https://doi. org/10.1161/JAHA.114.000790)
34 Holland OB, Brown H, Kuhnert L, Fairchild C, Risk M \& GomezSanchez CE. Further evaluation of saline infusion for the diagnosis of primary aldosteronism. Hypertension 19846 717-723. (https://doi. org/10.1161/01.HYP.6.5.717)

35 Funder JW, Carey RM, Fardella C, Gomez-Sanchez CE, Mantero F, Stowasser M, Young WF Jr, Montori VM \& Endocrine S. Case detection, diagnosis, and treatment of patients with primary aldosteronism: an endocrine society clinical practice guideline. Journal of Clinical Endocrinology and Metabolism 200893 3266-3281. (https://doi.org/10.1210/jc.2008-0104)

36 Moon JC, Messroghli DR, Kellman P, Piechnik SK, Robson MD, Ugander M, Gatehouse PD, Arai AE, Friedrich MG, Neubauer S, et al. Myocardial T1 mapping and extracellular volume quantification: a Society for Cardiovascular Magnetic Resonance (SCMR) and CMR Working Group of the European Society of Cardiology consensus statement. Journal of Cardiovascular Magnetic Resonance 20131592. (https://doi.org/10.1186/1532-429X-15-92)

37 Messroghli DR, Moon JC, Ferreira VM, Grosse-Wortmann L, He T, Kellman P, Mascherbauer J, Nezafat R, Salerno M, Schelbert EB, et al. Clinical recommendations for cardiovascular magnetic resonance mapping of T1, T2, T2* and extracellular volume: a consensus statement by the Society for Cardiovascular Magnetic Resonance (SCMR) endorsed by the European Association for Cardiovascular Imaging (EACVI). Journal of Cardiovascular Magnetic Resonance 2017 19 75. (https://doi.org/10.1186/s12968-017-0389-8)

38 Heiberg E, Sjogren J, Ugander M, Carlsson M, Engblom H \& Arheden H. Design and validation of segment - freely available software for cardiovascular image analysis. BMC Medical Imaging 2010 10 1. (https://doi.org/10.1186/1471-2342-10-1)

39 Flett AS, Hasleton J, Cook C, Hausenloy D, Quarta G, Ariti C, Muthurangu V \& Moon JC. Evaluation of techniques for the quantification of myocardial scar of differing etiology using cardiac magnetic resonance. JACC: Cardiovascular Imaging 20114 150-156. (https://doi.org/10.1016/j.jcmg.2010.11.015)

40 Taylor AJ, Salerno M, Dharmakumar R \& Jerosch-Herold M. T1 mapping: basic techniques and clinical applications. JACC: Cardiovascular Imaging 20169 67-81. (https://doi.org/10.1016/j. jcmg.2015.11.005)

41 Brilla CG. Aldosterone and myocardial fibrosis in heart failure. Herz 200025 299-306. (https://doi.org/10.1007/s000590050024)

42 Lijnen P \& Petrov V. Induction of cardiac fibrosis by aldosterone. Journal of Molecular and Cellular Cardiology 200032 865-879. (https:// doi.org/10.1006/jmcc.2000.1129)

43 Campbell SE, Diaz-Arias AA \& Weber KT. Fibrosis of the human heart and systemic organs in adrenal adenoma. Blood Pressure 19921 149-156. (https://doi.org/10.3109/08037059209077510)

44 Kong P, Christia P \& Frangogiannis NG. The pathogenesis of cardiac fibrosis. Cellular and Molecular Life Sciences 201471 549-574. (https:// doi.org/10.1007/s00018-013-1349-6)

45 Devereux RB, Wachtell K, Gerdts E, Boman K, Nieminen MS, Papademetriou V, Rokkedal J, Harris K, Aurup P \& Dahlof B. Prognostic significance of left ventricular mass change during treatment of hypertension. JAMA 2004292 2350-2356. (https://doi. org/10.1001/jama.292.19.2350)

46 Velagaleti RS, Gona P, Levy D, Aragam J, Larson MG, Tofler GH, Lieb W, Wang TJ, Benjamin EJ \& Vasan RS. Relations of biomarkers representing distinct biological pathways to left ventricular geometry. Circulation 2008118 2252-2258. (https://doi.org/10.1161/ CIRCULATIONAHA.108.817411)

47 Iwashima Y, Horio T, Kuroda S, Takishita S \& Kawano Y. Influence of plasma aldosterone on left ventricular geometry and diastolic function in treated essential hypertension. Hypertension Research 2002 25 49-56. (https://doi.org/10.1291/hypres.25.49)

48 Nakahara T, Takata Y, Hirayama Y, Asano K, Adachi H, Shiokawa G, Sumi T, Ogawa T \& Yamashina A. Left ventricular hypertrophy and geometry in untreated essential hypertension is associated

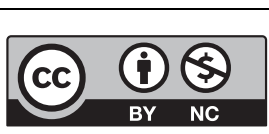

This work is licensed under a Creative Commons Attribution-NonCommercial 4.0 International License. 
with blood levels of aldosterone and procollagen type III aminoterminal peptide. Circulation Journal 200771 716-721. (https://doi. org/10.1253/circj.71.716)

49 Funder JW. Primary aldosteronism and salt. Pflügers Archiv 2015467 587-594. (https://doi.org/10.1007/s00424-014-1658-0)
50 Catena C, Colussi G, Novello M, Verheyen ND, Bertin N, Pilz S, Tomaschitz A \& Sechi LA. Dietary salt intake is a determinant of cardiac changes after treatment of primary aldosteronism: a prospective study. Hypertension 201668 204-212. (https://doi. org/10.1161/HYPERTENSIONAHA.116.07615)

Received in final form 5 February 2018

Accepted 12 February 2018

Accepted Preprint published online 12 February 2018
This work is licensed under a Creative Commons Attribution-NonCommercial 4.0 International License. 